\title{
Digital Pedagogy for Sustainable Learning
}

\author{
C. Nanjundaswamy \\ Professor, Department of Civil Engineering \\ Dr. Ambedkar Institute of Technology, Bangalore, Karnataka, India
}

\section{OPEN ACCESS}

Manuscript ID:

EDU-2021-09033881

\section{S. Baskaran}

Associate Professor, Department of $M B A$

Dr. Ambedkar Institute of Technology, Bangalore, Karnataka, India

Volume: 9

Issue: 3

Month: June

Year: 2021

P-ISSN: 2320-2653

E-ISSN: 2582-1334

Received: 01.04.2021

Accepted: 20.05.2021

Published: 01.06.2021

Citation:

Nanjundaswamy, C., et al. "Digital Pedagogy for Sustainable Learning." Shanlax International Journal of Education, vol. 9 , no. 3, 2021, pp. 179-185.

\section{DOI:}

https://doi.org/10.34293/ education.v9i3.3881

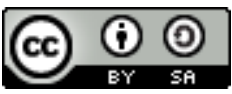

This work is licensed under a Creative Commons Attribution-ShareAlike 4.0 International License

\section{M.H. Leela}

Assistant Professor, Department of $M B A$

Dr. Ambedkar Institute of Technology, Bangalore, Karnataka, India

\begin{abstract}
Digital pedagogy is essential now as the entire world moves towards digitalization in all fields. Technology has influenced a lot on learning and resulted in the development of digital pedagogy, which has become a vital part of today's world. This paper focuses on the influence and benefits of digital pedagogy for sustainable learning. The multifaceted nature that supports the developing idea of sustainable learning is viable for collaborating and networking interdisciplinary. Introduction of common goals, shared values and means for sustainability become challenging to achieve until a rapid or fast advancement on data innovation and information technology, digital learning, and worldwide access to data, information communication technologies (ICT) and development of selforganized socio-technical networks. Another dimension for innovation is 'Susthingsout', which refers to a creative pedagogy with an enhanced teaching platform, improved e-magazine and virtual e-learning platforms. The word 'Susthingsout' means to uphold, encourage, and instill sustainable learning through the extensive and broad curriculum to the undergraduate course and various campus-based activities. In this regard, 'Education for Sustainable Development (ESD)' bridges the gap between the traditional and contemporary era that receives global acceptance and global reach. The present study outlines how contemporary platforms developed with unified efforts by combining experts, professionals, academicians, practitioners, learners and curriculum as a result of blended application on theory and practical knowledge and augments students' employability. The study aims to examine the viability of academic practice, skills beyond disciplines, the classroom and the institution. The conceptual model has been initiated on Digital Collaboration and Sustainable Learning. Therefore, collaborative learning, blended learning, flipped learning, open conversation, creativity and innovation are at the heart of education and it is a system for sustainable learning and development.
\end{abstract}

Keywords: Digital learning, Innovative pedagogy, Sustainable learning, Sustainable development

\section{Introduction}

Teaching always involves the concept of design which includes planning course content, methods and modes of teaching. This article outlines the background and aspirations of a new digital pedagogy devised to transform how a receiver perceives learning and education, which result in sustainable learning. Previous studies about digital pedagogy represent E-learning platforms, modes of learning, communication tools and equipment that facilitate collaborative and interactive teaching and learning among the participants without any constraint on time and place. Today, with the present pandemic situation, digital pedagogy has become a vital part of education, irrespective of higher and lower education. 
Earlier, it was only the part of higher and distance education, but now it is part of the whole education system. Therefore, this study focuses on digital pedagogy on sustainable learning based on secondary data.

The transformation in education via the development of ICT is overwhelming in the continuation of revolutionary support of the internet and utilization of network-linked devices. Accordingly, unique instructional and educational modalities have emerged, raising new situations and scenarios to shape different stages of training. Contemporary modalities for virtual training include the Massive Open Online Courses (MOOCs) platform, which utilizes ICT on e-materials, e-books, videos and e-transcript facilitating learning. These methods have been advantageous in their adaptability and remote utilization at any time and to increase the prospects of ubiquitous learning without any restriction on place and time. The limitation of these methodologies lies in the lack of interactions in a course, perhaps in a learner's motivation.

Further, e-learning, ICT-based modalities are mechanisms to improve access to education. Using such technological tools, the learner develops innovative solutions to the most prominent issues and problems that arise in the society. According to "United Nations Educational, Scientific and Cultural Organization (UNESCO)," "Education for sustainable development aims to give people the skills and knowledge to find solutions to economic, social, and environmental problems. It encourages students to reflect on excess consumption, poverty, the stimulation of solidarity and cooperation, and to recognize that current economic development trends are not sustainable". In turn, it has created an obligation for each institution to inculcate these requirements among its programs.

Pedagogy is a teaching method, and it is adopted by a teacher, which involves teaching styles, theory, assessment and feedback. Pedagogy depends on various factors such as the social system, the content of information, and the receiver. An individual expresses the pedagogy of teaching by referring to the educator, style of delivery on the content to the class. While a trainer plans a lesson, he will consider various methods to deliver the knowledge and information influenced through his effective training preferences, experience, and choice of context. There are several reasons behind his decisions to use effective pedagogical principles, and overtime every educator adopts his/her pedagogical principles.

Pedagogy methods broadly classified into:

- Teacher-centric pedagogy

- Learner-centric pedagogy

- Learning-centric Pedagogy

- Interactive or Participative pedagogy

Sustainable Learning is an innovative idea to create and increase sustainable courses and methodology of learning and teaching that infuse in the learner the skills and outlook to prosper in the complex and challenging state of affairs and positively contribute to make the world a better place.

\section{Background}

Early 20th Century, Digital pedagogy was first introduced in distance learning, in which course materials were delivered through the mail. Later, it was believed that radio and television would bring in a rapid change in the course of education. . the University of Louisville, with the cooperation of The National Broadcasting Company (NBC) in the United States, created many Educational programs Television and radio broadcasts. During the 1980s and 1990s, the Association for Computers and the Humanities (ACH) has offered events like workshops and conferences on teaching computers and the humanities. The National Endowment for the Humanities (NEH) was established in 1965 and organized International Conference on Digital Pedagogies in a different country every year. In addition, several distance education systems brought a direction and online education that has become more popular now in this pandemic situation. With the drastic shift from offline to online, teaching and learning are complex, problematic and evolutionary. However, it can be managed.

Conspicuously, ample literature discloses that digital pedagogy faces some problems due to lackof-coordination between learners and teachers, technological problems, attitudinal difference, fear of new technology and fear of losing reputation. Online learning based on constructivism is found to 
be dissimilar to learning in a conservative classroombased setting. The contributions of 'Digital Forum' transformed the studies' of the nineteenth-century and brought a new teaching and learning process. It has enriched the classroom through 'digital resources' across various disciplines by enabling the development and methodologies of the new project.

\section{Objectives}

- To study the importance and benefits of digital pedagogy.

- To recognize the influence of digital pedagogy on sustainable learning.

- To identify the challenges and offer solutions in digital pedagogy.

- To develop a conceptual model on digital pedagogy

- To examine the viability of the academic practice, skills beyond disciplines, the classroom and the institution

\section{Methodology}

The study is conceptual. The secondary data has been sourced through websites, eBooks, and publications.

\section{Importance and Benefits of Digital Pedagogy}

Digital pedagogy values open education renovated from a space where users passively retrieve data and information, conveyed by specialists to a participatory, verbal, or non-verbal platform's extended communication ability. At present, technology 'web 2.0' includes 'Social Networking Applications,' 'Blogs,' 'Wikis,' 'Webbased Presentation Tools,' and 'Online Mind Mapping Tools. In particular to higher education, the institutions promoting unique and innovative approaches, methodology, tools, and techniques to integrate ICT and pedagogy at various educational levels. The use of technology is an inseparable part of digital pedagogy, and it is advantageous only within the framework of fitting pedagogy. However, any "Technology cannot serve as a substitute for the Teacher."

In the 21 st Century, the new culture of Teaching and Learning has evolved with the emergence of Information and Communication Technologies.
ICT has led to sweeping changes in $\mathrm{T} \& \mathrm{~L}$ process and offers ample opportunities for the learning community. At present, digital pedagogy has been increasingly augmenting the teacher-student relationship. It is found to be teacher-friendly and student-centric to reap many benefits from the participation of the learner community. Firstly, Learning Culture has prominently increased with the usage of Web platforms and tools of ICT. ICT tools are more convenient and affordable and generic. 'New ICT skills' with 'New Literacy' are not limited to reading paper, books, and texts. Proficiency in Word Processing skills creates a close link between literacy and Language development. Database and spreadsheets, Blogs, Wikis ("What I Know Is"), emails, web design and creation, skills on web search, programs on drawing and graphs, digital videos, even other gadgets like webcams, walkietalkies, software on audio and video recordings encourage development on $\mathrm{T} \& \mathrm{~L}$ for speaking and listening skills. By building autonomy, selfconfidence, self-determination, freedom, a healthy culture of teaching \& learning motivates learner communities to find their inner creativity, selfsufficiency, enthusiasm and become trendsetters in particular to higher education. Secondly, innovation and creativity grew to concentrate and imbibe among students' community to instill creativity and build their interest in exploring new ideas, knowledge, and skills. Mobile learning can be made possible through creative teaching-learning strategies and academic support strategies to develop support and enhance learner-driven innovation. Personalized learning experiences spread benefits to distinct learners, thus increasing the chances of the aspirant learner to have good skills and knowledge. Thirdly, student engagement, empowering students with accessible resources with the support of digital platforms could be beneficial to interact, contribute, reconfigure, share, and redeploy information and resources. Fourthly, with Open Educational Resources (OER) collaborated, T \& L collectively share information, resources and knowledge. Digital pedagogy ensures access to geographically dispersed experts, involves a multidisciplinary approach and exchange of knowledge. Importantly, T \& L has more flexible at any time and from any place without limiting the 
educators' creativity. However, digital pedagogy contributes to high-quality educational process, reaching and connecting remote students for any data, information, or resources and transformed capabilities of both teacher and learner without harming the educational system.

\section{Influences of Digital Pedagogy}

Digital pedagogy has become a study to employ up-to-date digital technologies in teaching and learning, perhaps applied to the learning environment either online or face-to-face. It allows reading, accessing, retrieving, and reacting to course materials on digital platforms and devices such as mobile phones, tablets, PCs and laptops. In India, statutory bodies like AICTE, UGC promote digital Pedagogy by making it obligatory in the curriculum. It is not only using digital technologies in teaching rather, using ICT platforms from a critical pedagogical perspective and utilize electronic devices to augment the experience of education.

Digital technology is influenced through the following concepts like MOOCs (Massive Open Online Courses), online discussion forums, LMSs (Learning Management Systems), Gamebased learning and its environments, Computer programming, Coding, and Virtual and Augmented realities, "BYOD" (Bring Your Device), "BYOT" (Bring Your Technology), "BYOC" (Bring Your Connectivity), "Maker Spaces," "Blogging," "MicroBlogging," "Wikis," "BackChannels," “Audio Recording and Music Making," "Image and Video Editing," "Creation of InfoGraphics," "Slideshows and Presentations," "Digital Storytelling," "Social Media," "Collaboration Tools and Mobile Apps". Further, Sustainable Learning is an innovative idea to create and increase sustainable courses and methodology of learning and teaching that infuse in the learner the skills and outlook to prosper in the complex and challenging state of affairs and positively contribute to make the world a better place. Creating virtual or physical 3D models, Software for Statistical analysis, Analytics, Gesturebased interfaces and Rubric generators are the important learners' access technologies. An online response system includes survey and voting polls, video conferencing, cloud computing.

\section{Challenges of Digital Pedagogy}

The Digital era at present in India brought widespread challenges to the educational sector. Digital technologies bring in new opportunities and challenges for teachers. Incorporating identified new opportunities in academia into the curriculum and instructionalstrategies and practices posesasignificant challenge for teachers and policymakers. Firstly, the barriers are integrating ICT in teaching \& learning with limited time, resources, and technical support. Secondly, the barriers are teachers' beliefs in ICT and their utilities, skill enhancement and practices in the classroom. While the traditional teaching approach has been gradually losing and decreasing its lure, the learners in the current era need different skills like effective communication skills, critical thinking and innovative skills, thinking creatively, problemsolving ability, negotiation and collaboration skills to accomplish expected results. The most common challenges for the teaching fraternity are updating and developing skills systematically to suit the radical change in digital pedagogy. The ICT usage has been tremendously increasing and becoming the need of an hour. Integration of ICT in T \& $\mathrm{L}$ is viewed as a revolutionary educational change in terms of high-tech education, in particular to higher education. Through the application of electronic bases such as multimedia, productivity software, and cloud computing, digital pedagogy focuses on ICT technologies, tools and skills, modes of operation in the digital world. Digital pedagogy in $\mathrm{T} \& \mathrm{~L}$ is found to be difficult. However, it is significant and essential for an educator to play a vital role as a promoter, motivator, and transmitter on a quest for knowledge. There are several difficulties that teachers face in incorporating ICT into the $\mathrm{T} \& \mathrm{~L}$ process. Constantly, the teaching fraternity must develop and maintain their pedagogy to keep abreast with the latest technologies. It is important to track the productivity of teacher-student interaction and ensure the sense of autonomy among the learners. In this line, the efficiency and effectiveness of learners increase to handle real-life challenges on their own.

Consequently, it is crucial for every teacher to recognize the learner's strengths, wants and needs to make interactions meaningful and teachers have to create the appropriate teaching ambiance, style. 
Nowadays, the current generation of students is active learners', appetite for technology and enthusiastic. It is a big challenge for the entire teaching fraternity to create a sustainable future. Therefore, teachers are required to be more innovative and creative in designing their instructional strategies. Creating awareness, learning engagement $\&$ active participation must be well addressed by the teachers in the usage of Digital Pedagogy.

\section{A Conceptual Model on Digital Collaboration and Sustainable Learning}

The model aims to establish sustainable learning and development of students through imbibing digital literacy about teaching $\&$ learning. In addition, each student is actively involved with faculties to design, develop \& deliver resources for teaching \& learning.

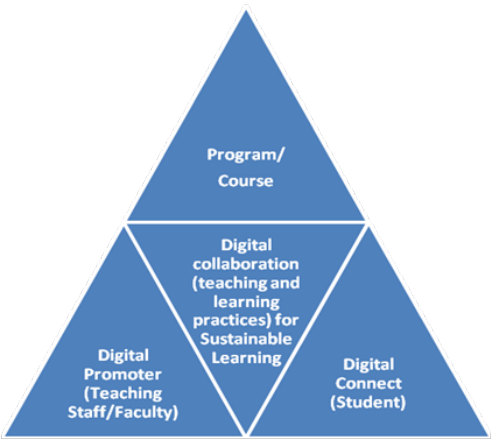

\section{Conceptual Model of Digital Collaboration and Sustainable Learning}

The designed model is dedicated to combining the program, the faculty, and the students with the digital collaboration to identify technology usage to design, implement and evaluate a new or enhanced digital practice within a course. Digital promoter, a faculty member who is digitally experienced who provides insights to enhance and improve their digital materials on courses. Digital connect, a student or participants with willingness, awareness, experience and confidence in the broad range of digital pedagogy and its approaches will provide this expertise.

\section{Findings}

The shift from paper to digital mode of pedagogy transforms the education system, which has both positive and negative outcomes. It is a powerful tool in the present world for sustainable learning.
- Digital pedagogy provides an opportunity for customized learning where students can get multidimensional knowledge from multi directions.

- In Digital Learning, learning happens simultaneously at different places and times. That is why digital pedagogy is extending learning opportunities worldwide.

- The shift to digital is motivating to both learners and trainers as it saves time and physical energy.

- Digital pedagogy encourages continuous feedback through assessments and adaptive learning and it allows self-analysis.

- Digital pedagogy empowers collaboration. Collaboration via Google Docs made it easy to communicate among team members.

- Learners get an advantage to prepare and produce specialized products and ideas to share among public audiences through presentations and publications. Digital tools help better in writing.

- Platforms to share course contents and supportive learning materials made it possible for millions of teachers within limited energy, time and cost, which reduced the cost and improvising their effective working environments \& calling for opportunities.

- Next-generation instructional systems personalize digital and printing options in new and exciting ways regularly.

- Digital pedagogy has been transforming the world and boosting millions of aspirants to connect with less expense.

- Digital pedagogy integrates Information and Communication Technology platforms to enable content on a particular course and encourages learning outcomes.

- Sustainable learning is viable for collaborating and networking interdisciplinary.

- 'Susthingsout,' virtual-based e-learning platform upholds, encourages, and instills sustainable learning through the extensive and broad curriculum to undergraduate course along with various campus-based activities.

- Teaching with technology can have a tremendous impact on student motivation in a classroom and plays a vital role as a promoter, motivator, and transmitter on a quest for knowledge.

- They were teaching with technology resulted 
in students' high-level involvement in learning. Although some students found the technology an obstacle to their learning, many students support the technology in a manner that brought them to a deeper conceptual understanding.

- Digital technology engages pupils in lifelong learning. Pupil need not visit an educational institution for learning they can learn wherever and whenever can learn.

- Digital Pedagogy encourages cross-cultural knowledge for learners. The process helps students together to communicate and study with people living in different geographical domains.

- Technology makes learning more attractive and interesting; learners can use videos, graphics, websites, apps and programs during the teaching and learning process.

- The designed model on digital pedagogy is dedicated to combining the program, the faculty, and the students with the digital collaboration to identify technology usage to design, implement, and evaluate a new or enhanced digital practice within a course.

- Digital Pedagogy has recognized and has created an obligation in every educational institution to inculcate Education for sustainable development, aiming to provide learners the skills and knowledge to find solutions to economic, social, and environmental problems in their programs.

- Learners access technologies to create awareness on virtual or physical 3D models, software for statistical testing, gesture-based interfaces and rubric generators, \& possibilities on figure tip usage of online response systems for online survey voting polls, video conferencing, cloud computing.

- In India, statutory bodies promote digital Pedagogy by making it obligatory in graduation to augment education experience.

- Increasing student engagement, empowering learners with accessible resources with the support of digital platforms could be beneficial to interact, contribute, reconfigure, share, redeploy and share information and resources.

\section{Problems}

- Learners may not involve completely as there is no physical interaction between trainer and learner.

- Technical issues like low internet speed and other software issues may disturb learning.

- Learning through digital tools may not suit all learners. All may not have such an academic discipline to meet the timeline.

- The joy of group learning is missing in this process. This may lead to isolation and consequent depression as well.

- The conservative and age-old teachers may find digital pedagogy as difficult to follow. They may even see it as a threat to their job security and shun technology altogether.

\section{Suggestions}

- Learning should be more interactive.

- Teachers should utilize all available trends which can keep learners more attentive.

- Increasingly, educators are made to adopt, utilize and practice integrated ICT technology in teaching to bring the change among students to learn better. So it is very much essential to train teachers to adopt new technology.

- Technologically more standard and accurate platforms should be developed to overcome technical problems.

\section{Conclusion}

Digital pedagogy is more innovative and it makes learners acquire skills from all directions beyond the course content. Learners can focus more and continuously learn from digital pedagogy, which has no time and physical frame. It inspires pupils to learn more effectively, which results in sustainable learning.

In the 21 st Century, the culture of teaching and learning is mandated to grow in education. The current era is expected to develop educators, learners, infrastructure and a supportive environment. There are several incidents that have reduced student interest and morale due to lack of technological advancement at classrooms and laboratories. The sustainable learning environment must facilitate effective instructional tools and equipment and 
boost high-tech infrastructure in laboratories and classrooms. It is evident that focused on teaching and learning-based digital pedagogy and digitalized education setup have a definite transformation for sustainable learning. However, the development of digital pedagogy with the influence of ICT platforms can take a huge step towards transforming both educators and learners. Therefore, creative pedagogy, virtual learning in any place and any time concept are speeding up learning and teaching. It has been observed that many factors, challenges, are there in creating capable digital pedagogy for sustainable learning. Thus, as long as teacher adaptability on digital pedagogy is good, it can serve learners and create bonding without technology. Hence, "Technology cannot serve as a substitute for the Teacher," and it retains both the educator and learner relationship as a whole.

\section{References}

Ark, Tom Vander. "The Shift to Digital Learning: 10 Benefits." Getting Smart, 2015.

Beetham, Helen, and Rhona Sharpe. Rethinking Pedagogy for a Digital Age: Principles and Practices of Design. Routledge, 2019.

Castro, May Portuguez, and M.G. Gomez Zermeno. "Challenge Based Learning: Innovative Pedagogy for Sustainability through e-Learning in Higher Education." Sustainability, 2020.

Coll, Sandyha. "Pedagogy for Education on Sustainability: Integrating Digital Technologies and Learning Experiences Outside School (LEOS)." University of the South Pacific, vol. 1, 2016, pp. 1-25.

Dangwal, Kiran Lata, and Shipra Srivastava. "Digital Pedagogy in Teacher Education." International Journal of Information Science and Computing, vol. 3, no. 2, 2016, pp. 67-72.

“Digital Pedagogy." Wikipedia, https://en.wikipedia. org/wiki/Digital_pedagogy.

Mussell, James. "Using Digital Resources in the Class." Journal of Victorian Culture, vol. 16, no. 1, 2011.

Kioupi, Vasiliki, and Nikolaos Voulvoulis. "Education for Sustainable Development: A Systemic Framework for Connecting the SDGs to Educational Outcomes." Sustainability, 2019.

Lewin, Cathy, et al. "Developing Digital Pedagogy through Learning Design: An Activity Theory Perspective." British Journal of Educational Technology, vol. 49, no. 6, 2018.

Scharmer, C. Otto. Theory U: Leading from the Future as It Emerges. Berret-Koehler Publishers, 2009.

Sipos, Yona, et al. "Achieving Transformative Sustainability Learning: Engaging Head, Hands and Heart." International Journal of Sustainability in Higher Education, vol. 9, no. 1, 2008, pp. 68-86.

Takala, Annina, and Kati Korhonen-Yrjänheikki. "A Decade of Finnish Engineering Education for Sustainable Development." International Journal of Sustainability in Higher Education, vol. 20, no. 1, 2019, pp. 170-186.

Vartiainen, Henriikka, and Jorma Enkenberg. "Reflections of Design-Oriented Pedagogy for Sustainable Learning: an International Perspective." Journal of Teacher Education for Sustainability, vol. 15, no. 1, 2013.

Willimson, Ben, et al. "Pandemic Politics, Pedagogies and Practices: Digital Technologies and Distance Education during the Coronavirus Emergency." Learning, Media and Technology, vol. 45, no. 2, 2020, pp. 107-114.

\section{Author Details}

C. Nanjundaswamy, Professor, Department of Civil Engineering, Dr. Ambedkar Institute of Technology, Bangalore, Karnataka, India

S. Baskaran, Associate Professor, Department of MBA, Dr. Ambedkar Institute of Technology, Bangalore, Karnataka, India, Email ID: rsbkaran.mba@drait.edu.in

M.H. Leela, Assistant Professor, Department of MBA, Dr. Ambedkar Institute of Technology, Bangalore, Karnataka, India 